\title{
Developments in the health service: the role of the Department of Health
}

\author{
N P Halliday MD QHP \\ Senior Principal Medical Officer, Department of Health, Eileen House, 80-94 Newington \\ Causeway, London SE1 6EF, England.
}

This paper addresses the Department of Health's role in the policy for the development of clinical services in the National Health Service (UK) (NHS). First it describes the way in which the arrangements have developed over the years and then considers what the future arrangements might be.

Although the Department of Health has an interest in all clinical services provided in the NHS and although we endeavour to keep up to date with developments in these services, the Department does not have an explicit policy for all of these services. Policy is formulated in clinical services only where there are pressing reasons so to do. The pressure for policy action may come from the public, parliament, the health professions and from pressure groups. For the vast majority of services, ministers have left the responsibility for the provision of such services to health authorities. Before I describe the arrangements by which the Department becomes directly involved in issuing guidelines or in promulgating policies on planning, designation, and the provision of services, I should like to mention a medical advisory body which can influence the manner in which services develop.

The Standing Medical Advisory Committee (SMAC) is a statutory body set up in 1948 to advise government ministers on medical matters. The membership of the committee is equally balanced between general practitioners and hospital doctors and between specialties in the case of hospital doctors. It is an independent committee; although serviced by the Department it is free to set its own agenda and to consider any medical issue it thinks appropriate. The

Paper read at the First European Conference on Domiciliary Ventilation and High Spinal Cord Lesion, Southport, England, October 1991. reports of SMAC over the years have been very influential in encouraging appropriate or discouraging inappropriate medical developments. An example of the influence SMAC can have is illustrated in the change in the surgical management of children with spina bifida after the publication of the SMAC report on this subject in 1974. The Department can at any time invite SMAC to address a problem relating to services or medical developments.

As I mentioned, a strength of SMAC is the fact that it is a balanced committee in terms of its membership, no one medical specialty having too much influence. When, however, the advice of one specialty is required or a very highly specialised area is to be addressed, the Department may go to the appropriate medical royal college or faculty, or indeed to the Conference of Medical Royal Colleges, and invite them to give advice to ministers on a specific subject. The Department makes great use of this route of obtaining advice.

The advice from SMAC or the royal colleges may cause the Department to act with respect to planning, development, and the provision of particular services. The key to the successful development and provision of clinical services is without doubt close cooperation between Departmental officials and members of the medical profession. Apart from the medical colleges which are the formal source of advice to the Department of Health, the Department is most fortunate in having available to it a number of other very cooperative medical professional bodies such as those associations and societies covering most of the medical specialties.

Because of its size the NHS requires careful planning if the services are to be developed in anything like a sensible pattern. The history of the planning arrangements explains to some extent the position 
in which we now find ourselves. The first major planning step towards a nationally planned service occurred in 1974. In that year the NHS underwent the first major reorganisation since 1948. As part of the reorganisation the NHS planning system was introduced, and was regionally based.

It was recognised that some services that should be planned on the basis of a population larger than the average region, that is 5 million or more, would not fit neatly within a regional planning system. The medical profession was concerned about the arrangements for funding 'medical developments'. The Department therefore attempted to deal with two aspects of medical developments. The first was the issue of those clinical services which for clinical and economic effectiveness should be planned and provided on the basis of a catchment population of 5 million or more and the second was the question of clinical services emerging from the research phase into the critical service development stage.

The medical profession was anxious to see some arrangements introduced to fund such medical developments. In addition the government and health authorities were concerned to assess and evaluate such developments both in terms of clinical effectiveness and economic effectiveness and value for money. As a result of such concerns a system for funding and evaluation of medical developments was introduced in 1974 in parallel with the NHS planning system.

The system introduced was the special medical development arrangements. Briefly the way the arrangement worked was as follows:

Where a service was about to emerge from a successful research phase and was one of general importance to the NHS, consideration was given to funding and evaluation of that service. The first step was to have the protocol of the bid referred by three experts in the field. If the referees supported the bid, the Department then considered funding the 'medical developments' for a period of 3 years. During these 3 years the development was evaluated both in terms of clinical and economic effectiveness, and the likely place of such a service in the NHS was given careful consideration, so that the introduction could as far as possible be planned.

Over the ensuing two decades these arrangements were found to be very effective. A number of services have been evaluated using the special medical development initiatives and have found their way into the service at regional or district level. Others have been successfully evaluated and have emerged as supraregional services. Examples of the latter include the evaluation of heart transplants, management of acute liver failure, endoprosthetic bone replacement, and stereotactic radiotherapy.

\section{Supraregional services arrangements}

As I mentioned earlier, when the NHS planning system was being prepared it was recognised that there were clinical services which did not fit the regional/district format, and were defacto supraregional in nature. Attempts were made to include an arrangement in the planning system for such services, but the number was so large that a meaningful system could not be devised. The deficiency was clearly recognised and ministers of the day set up an expert group to consider what might be done. The expert group failed, as had the civil servants before them, to come up with a solution. For a time therefore it was accepted that it was not possible to introduce such a system. The introduction of a formal planning system sharpened up the way in which the provision of services was planned, and brought into focus the problems facing supraregional services. The providers of these services often found themselves in conflict with providers of district services and competing for resources. As a result of pressure from the medical profession a joint working party, made up of medical staff from the Department and members of the Joint Consultants Committee (JCC), was established in 1977/78.

\section{Joint DHSS/JCC Working Party}

The major concern of the JCC members was to safeguard 'medical developments'. The 
immediate difficulty was in agreeing a definition of a medical development. The working party after some years of deliberation (1977-1983) finally recommended that the following activities should be excluded from consideration: Postgraduate and undergraduate medical education; medical research; medical developments, because of the difficulties already mentioned and the fact that the SMD arrangements existed; diagnostic services (unless as an integral part of an already designated service); and equipment per se. By excluding such services it appeared that a mechanism might be found to fund those services which should be concentrated in a few units on a supraregional basis in order to be both clinically and economically viable.

The working party recommended that in selecting services for consideration the main emphasis should be on the rarity of the condition rather than the number of units, ie the population served would be substantially more than 5 million people.

\section{The Supraregional Services Advisory Group}

The present arrangements were introduced in 1983 and circular $\mathrm{HN}(83) 36$ gives the details of the arrangements and of the advisory group, which would advise the Secretary of State on the services to be designated and on the appropriate level of provision. The circular defined a supraregional service as the small number of specialised health services which, in order to be economically viable or clinically effective, need to be provided for a population substantially larger than that of any one region'. It goes on to detail the other criteria all of which must be met. The criteria are:

1 The service should be an established clinical service, and not a research or development activity.

2 There should be a clearly defined group of patients having a clinical need for the service.

3 The benefits of the service should be sufficient to justify its cost when set against alternative uses of NHS funds.

4 The cost should be high enough to make the service a significant burden on the providing region.
5 Supraregional funding, as opposed to regional or subregional, should be clearly justified (a) by the small number of potential patients in relation to the minimal viable workload for a centre; or (b) by the economic and service benefits of concentrating the service in fewer and larger units shared between regions (this does not include services organised mainly at regional level in which two regions agree on joint provision as a matter of mutual convenience); or (c) as an interim measure, by the scarcity of the relevant expertise and/or facilities; or (d) by the units being designated capable of meeting the total estimated national caseload for England.

\section{The Department's approach to policy formulation}

Taking the subject of domiciliary ventilation, the first step is very much in the hands of those clinicians responsible for the management of patients with serious respiratory problems. What is the problem to be addressed? Is it the need to draw the medical profession's attention to the value of such a service, or is there already an acceptance by the medical profession that this is the treatment of choice for appropriate patients. By the medical profession I mean colleagues within the same specialty and the profession generally. If there is acceptance by the profession of the need for the service, are there any problems in making adequate provision of the service? Clearly there are affirmative answers to these questions or we would not have attended a conference to discuss these issues.

Whatever the answers to these questions may be, I would always encourage the clinicians involved to work up a paper or report which clearly sets out and makes the case for the service. The paper or report must be soundly based with a clear statement of the epidemiological data giving the incidence and prevalence of the condition to be treated, the criteria for selection of patients for such treatment, the benefits one can expect and, as far as one can estimate, a 
cost of the service. If one can compare the cost with alternative forms of treatment so much the better. One should, where appropriate, draw on such evidence from other centres.

The exercise of preparing a report ensures that one has considered most of the points for and against a service and achieved a measure of agreement with colleagues in the specialty. I would recommend that any such working groups consider the possibility of a Departmental observer being on the working group. The Departmental observer cannot influence the recommendations of the working party, and indeed is not bound by the working party recommendations, but at least the presence of an observer can assist the working party in selecting the most fruitful approach if ministerial or Departmental support is eventually required.

Once the paper has had the blessing of the appropriate medical royal college it becomes a valuable document making the case for appropriate provision of the service. In many instances, all that is necessary is for the Department to take receipt of the working party report and then promulgate the document to the NHS, commending the advice contained therein to the health authority's attention. Such a policy document, circulated by the Department, can have considerable influence in persuading purchasers to contract for the service.

This approach has been very effective in the past and will, I am sure continue to be effective in the future. There remain, however, some services which require direct Departmental involvement to ensure that the service develops in an acceptable fashion. In such cases the next step is for the the Department to take.

The first step is to confirm the medical royal colleges' support for the service case contained in the working party report. Such confirmation may be sufficient, but in some cases it is necessary to seek further advice from an independent medical source. As I have mentioned before that source is usually SMAC.

If SMAC recommends it, a service should be provided by the NHS. To be designated supraregional it would need to meet the strict criteria I have already mentioned. If the decision is that it should be provided within a regional or district setting then it would be necessary to ensure that the purchasers were made aware of the need. To date the way that this objective is achieved is by the preparation of a Department 'circular' setting out the Departmental policy which, after consultation and agreement, is sent to all general managers.

Establishing a new service or making innovative changes to an existing service is not without problems. It may take a number of attempts and a great deal of time and effort, but I would strongly recommend that whatever action one decides to take, preparing a well argued case in the form of a report which has the blessing of the apropriate professional bodies and medical royal colleges is a step to be recommended and one which will more than repay the effort involved. 